\title{
Does gallbladder cancer divide India?
}

\author{
Anu Behari · Vinay K. Kapoor
}

Cholecystectomy for gallstone disease is one of the most common abdominal surgical procedures. Histological examination of gallbladders (GB) removed during this surgery is routine in most pathology departments. However, in recent years, the necessity of routine histological examination has been questioned.

In this issue of the Journal, Mittal et al, from a center in southern India, report their experience with 1,312 cholecystectomies over a 10 -year period. ${ }^{1}$ Of these, 610 (47\%) GBs showed macroscopic abnormalities consisting of "thickening, mucosal ulcerations and polypoidal lesions". Gallbladder cancer (GBC) was found in 13 of these GBs, including nine that were "thick-walled", two with "mucosal ulcerations" and two with "nodularity of mucosa with polypoid projections". Presumably these macroscopic changes were no different from those seen in 597 GBs with macroscopic abnormalities but no GBC. None of the GBs without macroscopic abnormalities was found to have GBC. The GBC was stage Tis in one patient, T2 in nine and T3 in three patients. No information has been provided on whether the specimens contained cystic lymph nodes, and whether these were examined histologically. In patients with GBC, status of resection margin, and treatment and follow up details are not provided. However, it is evident that as many as nine patients who had T2 lesions could have benefitted from a re-resection. Based on their findings, the authors recommend a policy of selective histological examination of only those GBs which show macroscopic

\footnotetext{
A. Behari · V. K. Kapoor

Department of Surgical Gastroenterology, Sanjay Gandhi Postgraduate Institute of Medical Sciences, Lucknow 226014 , India

A. Behari $(\square)$

e-mail: anubehari@yahoo.co.in

(C) Indian Society of Gastroenterology 2010
}

abnormalities, to save costs and reduce workloads. We would like to introduce a strong note of caution in accepting this recommendation across all geographical areas.

GBC is the most common cancer of the biliary tract worldwide. $^{2}$ The overall prognosis remains grim with 5-year survival of less than 5-10\%. ${ }^{3}$ Potentially curative resection of the tumor and its loco-regional spread provides the only hope of long-term cure and survival. The extent of such resection may range from a simple cholecystectomy, through an extended cholecystectomy with a 2-cm nonanatomic wedge of liver in the GB bed in segments $\mathrm{IVb}+\mathrm{V}$ and lymphadenectomy, to an extended right hepatectomy and pancreatico-duodenectomy, depending upon the location and spread of the tumor.

Curative resection is possible in only those few patients who have a tumor that is limited to the GB wall without involvement of the lymph nodes or adjacent structures in the hepato-duodenal ligament. ${ }^{4}$ A highly select sub-group of patients with locally advanced, but non-metastatic, disease may benefit from extensive resections including hepatopancreatico-duodenectomy. ${ }^{5,6}$ However, in most patients, the disease is diagnosed at an advanced stage when curative resection is not possible; in these cases, radiotherapy, with or without chemotherapy, has little impact on survival. ${ }^{7}$

GBC diagnosed for the first time on histology of GB removed with a presumed diagnosis of gallstone disease is known as incidental GBC (IGBC). The term IGBC should not be used when GBC is suspected either on pre-operative imaging (ultrasonography [US] or CT scan), during surgery or on opening the GB specimen.

Management of IGBC is primarily guided by the extent of transmural spread ( $\mathrm{T}$ stage) of the tumor. The chances of lymph node involvement and residual disease in the GB fossa increase with increasing $\mathrm{T}$ stage. While simple cholecystectomy without lymphadenectomy, which has already been done, is considered sufficient for tumors limited to the GB mucosa (T1a), a re-operation with liver resection and lymph node clearance (completion extended cholecystectomy) is recommended for tumors extending to the 
muscle coat (T1b) and beyond. Significant survival benefit of re-resection has been well-documented for tumors reaching the peri-muscular connective tissue (T2). ${ }^{8-10}$ Some prolongation of survival has also been reported for selected T3 tumors. ${ }^{8,11}$ Re-resection may also be required in patients with node-positive disease; this requires histological examination of the cystic lymph node in addition to the GB.

Early stage tumors, which are most likely to benefit from surgical resection, are difficult to diagnose pre-operatively. ${ }^{12}$ This is especially true when GB contains stones, which make it difficult to detect a small area of thickening or small mass lesions on abdominal US. Long-standing gallstone disease with GB wall thickening due to chronic cholecystitis and xantho-granulomatous cholecystitis (XGC) (a variant of chronic cholecystitis) may make this detection even more difficult. ${ }^{13}$ Many of these lesions are not apparent even on gross examination of the GB. Thus, in various reports, IGBC forms a significant percentage of resected GBCs. ${ }^{14,15}$ Since there are no clinical pointers to early GBC, these patients are usually subjected to a cholecystectomy for the associated gallstone disease and the cancer is discovered for the first time on histological examination of the removed GB. With the easy availability of US and ever-increasing popularity of laparoscopic cholecystectomy, there is a perception that an increasing number of early stage GBCs are being picked up. ${ }^{16}$ This may, however, merely reflect increasing number of cholecystectomies.

One of the unique features of GBC is the striking gender, geographic and ethnic variation in worldwide incidence, suggesting a strong influence of genetic and environmental factors. GBC is rare in most of Northern Europe and North America. $^{2}$ The highest rates of GBC are found in northern India and Pakistan, East Asia (Korea and Japan), Eastern Europe (Slovakia, Poland, and Czech Republic), and South America (Columbia and Chile). Rates may vary even within a region or a country. Incidence of GBC in women in northern India is as high as 9 per 100,000 per year as compared to as low as 1 per 100,000 per year in southern India. ${ }^{17} \mathrm{In}$ areas of high prevalence, GBC is one of the most common gastrointestinal cancers, especially in women.

The association between gallstones and GBC continues to mystify clinicians. The parallels in epidemiology between the two are striking. The risk of GBC increases with increasing size and number of gallstones, especially if the stones occupy a significant volume of the GB. ${ }^{18}$ Progressive changes in GB walls from chronic cholecystitis, hyperplasia, metaplasia, dysplasia, carcinoma in-situ, to invasive cancer over time have been reported from Chile. ${ }^{19}$ Based on these data, surgeons in Chile recommend prophylactic cholecystectomy in patients with gallstones - at the age of 30-40 years in women and 40-50 years in men. ${ }^{20}$ The incidence of GBC is also reported to be higher in patients with XGC and Mirizzi's syndrome, both of which are associated with long-standing gallstone disease. ${ }^{13,21}$ The rela- tionship between gallstones and GBC is however complex, since GBC is uncommon in many geographical areas where gallstones are common and GBC can also occur without gallstones.

Several recent reports have questioned the need for routine histology of all removed GBs. ${ }^{22-27}$ This is based primarily on cost-benefit considerations, a very low likelihood of missing an early cancer and the observation that almost all incidental GBC are associated with findings on gross examination of the GB when the GB was cut open and examined. Since a "normal-looking" GB is thought unlikely to harbor a malignancy, selective histopathological examination of only those GBs which have suspicious changes on macroscopic examination may suffice. It has further been argued that for very early tumors (Tis and T1a), simple cholecystectomy is adequate treatment and no further therapy is required. A selective policy may thus significantly reduce the workload of pathologists, is costbeneficial, with no added risk to the patient.

A review of literature on this issue reveals that most of these reports are from the UK and France, areas with low incidence of GBC (Table 1). Most of the cases of GBC in these reports were obvious on gross examination of the GB and many were actually suspected on pre-operative imaging. Thus, strictly speaking, these were cases of GBC that were actually picked up pre- or intra-operatively, and the true incidental GBC were even less frequent. These were seen in the GBs described as "thick walled" and often with significant acute inflammation - either acute cholecystitis or empyema. Most cases were advanced and no further therapy was considered; prognosis was uniformly poor. With such low rates of detection of disease necessitating any change in management, authors proposed a selective policy of examining only grossly suspicious GBs. It may be noted, however, that one of these reports recommended that "as the incidence of gallbladder malignancy starts to rise after the age of 50 years, the threshold for histological examination may need to be lowered in this age group". ${ }^{22}$

In most geographical areas with high incidence of GBC, especially those where the prevalence of gallstones is also high (such as northern India and South America), most GBs have changes of chronic cholecystitis and many show presence of XGC. Our experience with thick walled GBs and incidental GBC (unpublished data) highlights some of these issues. In a study that included a total of 60 consecutive patients with a thick-walled GB ( $>3 \mathrm{~mm})$ on abdominal US, histology of GBs after cholecystectomy showed GBC in only $2(3.3 \%)$ patients. These GBs were indistinguishable at operation from the remaining 58 patients with chronic cholecystitis, of whom 28 (48\%) had XGC. ${ }^{28}$ Despite our high index of suspicion for GBC, and careful macroscopic examination of all GBs after removal, as many as 44 out of approximately 5000 cholecystectomies done in our department had an IGBC which was not suspected at 
Table 1 Reports addressing selective histology of removed gallbladders

\begin{tabular}{|c|c|c|c|c|c|c|c|c|}
\hline Author Ref & Country & $\begin{array}{l}\text { Cholecys- } \\
\text { tectomies } \\
\text { (n) }\end{array}$ & $\begin{array}{c}\text { Duration } \\
\text { of study } \\
\text { (years) }\end{array}$ & $\begin{array}{c}\text { Incidental } \\
\text { GBC } \\
(\mathrm{n}[\%])\end{array}$ & $\begin{array}{l}\text { T stage } \\
\text { of GBC } \\
\text { (n) }\end{array}$ & $\begin{array}{c}\text { Macroscopic } \\
\text { lesion }\end{array}$ & $\begin{array}{l}\text { Pre-operative } \\
\text { suspicion }\end{array}$ & Recommendation \\
\hline Darmas $^{22}$ & UK & 1452 & 5 & $4(0.27)$ & $\begin{array}{l}\text { T2No: } 2 \text {, } \\
\text { T2: } 1, \\
\text { T4No: } 1\end{array}$ & Mass in all & $2 / 4(50 \%)$ & Selective HP \\
\hline Taylor $^{23}$ & UK & 1078 & 7 & $6(0.55)$ & NA & $\begin{array}{l}\text { Thick walled GB in } \\
\text { all, suspicious of } \\
\text { GBC in all }\end{array}$ & $2 / 6(33 \%)$ & Selective HP \\
\hline $\operatorname{Dix}^{24}$ & UK & 1308 & 4 & $5(0.3)$ & NA & $\begin{array}{l}\text { Suspicious in all- } \\
\text { raised/solid lesions, } \\
\text { multiple nodules, } \\
\text { nodes at porta }\end{array}$ & $3 / 5(60 \%)$ & Selective HP \\
\hline Matthyssens $^{27}$ & France & 1523 & 10 & $4+2 *(0.4)$ & NA & $\begin{array}{l}\text { All had suspicious } \\
\text { nodules/local } \\
\text { indurations }\end{array}$ & NA & Selective HP \\
\hline Bazoua $^{26}$ & UK & 2890 & 10 & $5(0.17)$ & $\begin{array}{c}\text { T2: } 1, \\
\text { T3: } 3, \\
\text { T4: } 1\end{array}$ & $\begin{array}{l}\text { Suspicious in } 2 \text {; } \\
\text { thick walled in all }\end{array}$ & $2 / 5(40 \%)$ & Selective HP \\
\hline Oommen $^{25}$ & UK & 976 & 4 & $1(0.1)$ & & & & Selective HP \\
\hline Lohsiriwat $^{29}$ & Thailand & 4317 & 8 & $24(0.56)$ & $\begin{array}{l}\text { T1: } 11, \\
\text { T2: } 11, \\
\text { T3: } 2\end{array}$ & $\begin{array}{l}\text { No intra-operative } \\
\text { suspicion }\end{array}$ & None & Routine HP \\
\hline
\end{tabular}

GBC: gallbladder cancer; HP: histopathology; NA: not available; *lymphoma

operation or in the GB specimen (unpublished data). The thick walled, small, contracted GBs were indistinguishable from those that we often see in patients with long-standing gallstone disease.

Many other reports support the observation that changes of acute inflammation, especially empyema, and thick fibrotic walls in chronic inflammation make it difficult or impossible to diagnose GBC on macroscopic examination. Lohsiriwat et al noted that one third of their incidental GBC patients had GB empyema and reported that a clinical diagnosis of empyema and patient age $>60$ years were the two significant risk factors for IGBC on multivariate analysis. ${ }^{29}$ Reporting from Chile (with one of the highest incidence rates of GBC), Roa et al observed that " $37 \%$ of the primary tumors were macroscopically inapparent". 30

Though some patients with incidentally discovered GBC may be at a very early (Tis or T1a) stage and, therefore, no further management may be required, a significant number are likely to have early stage disease (T1b and T2) where further therapy with re-resection is likely to make a significant positive difference in prognosis. A review of reported cases of IGBC reveals that a significant number of IGBC are such early GBCs. T2 tumors (the ones most likely to benefit from radical reresection) constituted 59\% (43/73), 49\% (48/98) and 46\% (13/28) of incidental GBC reported by Wakai, Shirai and Toyonaga, respectively from Japan. ${ }^{9,10,31}$ Similar figures have been reported by other authors. ${ }^{32-34}$ In our 44 cases with IGBC, the $\mathrm{T}$ stage distribution was $\mathrm{T} 1 \mathrm{a}$ in 4 , $\mathrm{T} 1 \mathrm{~b}$ in 16 , T2 in 15, and T3 in 9 patients.

Recommendations for routine histology of GB specimens should take into consideration local incidence rates of GBC. A selective policy may be safe and costbeneficial in areas with very low incidence of GBC. This would include most countries of the West. In developed countries, patients with gallstones usually present for treatment soon after onset of symptoms. In majority of patients undergoing cholecystectomy for symptomatic gallstone disease, the GBs, thus, may not show changes of long-standing gallstone disease and chronic cholecystitis. Macroscopic changes suspicious of malignancy e.g., mucosal abnormalities, focal thickening, induration, etc. are more likely to be picked up easily on inspection of an opened GB and may help in selecting GBs that require histological examination. 
In areas with a high incidence of GBC and a high prevalence of gallstones, including northern India, GBs removed for presumed gallstone disease and its complications should be routinely examined grossly as well as microscopically as gross morphological changes of malignancy (GBC) may be indistinguishable from benign pathology (chronic cholecystitis and XGC). This would make it impossible to select GBs to be subjected to histology based on macroscopic findings alone and would increase the risk of missing potentially curable early stage GBC.

It is not uncommon in northern India to see a patient with a right upper quadrant abdominal mass, jaundice and gastric outlet obstruction a few months after cholecystectomy for presumed gallstone disease; GB was not sent for histological examination as it looked grossly normal - a clear case of "missed GBC". In fact 11 such patients with missed GBC were referred to us as suspected benign postcholecystectomy bile duct strictures for stricture repair. ${ }^{35}$ Had the GB been subjected to histological examination, a re-resection could have provided long-term survival, and may be even cure, in some of these patients. At the time of referral to us, all 11 patients with missed GBC were beyond cure.

Recommendation of selective histology of GB is based on the assumption that incidental discovery of a GBC in a routine surgical specimen is rare and will seldom change management of the patient. In case of GBC, this premise does not hold true, at least in geographical areas and ethnic groups where GBC is common. Gross changes of long-standing inflammation are indistinguishable from those of GBC and early, potentially curable GBC may be discovered on histological examination in GBs which are macroscopically indistinguishable from GBs without cancer. Re-operation and liver resection with lymph node clearance (completion extended cholecystectomy) would provide the same survival benefit as primary curative surgery in these patients, ${ }^{36}$ while missing these cancers would mean sure death from disease recurrence and progression. In a disease as aggressive and lethal as GBC this is a chance of cure that can not and should not be denied to the patient.

We strongly advise that all GBs removed for presumed gallstone disease should be opened up by the surgeon in the operating room for a careful gross examination. If changes suspicious of malignancy are seen, the GB should be subjected to a frozen section examination and if it is positive, an extended cholecystectomy should be performed. If no changes suspicious of malignancy are seen, at least in northern India, the GB should be subjected to routine histological examination to detect an incidental GBC so that reresection with a hope for long-term survival may be offered to the patient.
Gallbladder cancer does seem to divide India between a north and a south but nothing else can.

\section{References}

1. Mittal R, Jesudason MR, Nayak S. Selective histopathology in cholecystectomy for gallstone disease. Indian J Gastroenterol 2010;29:32-36.

2. Diehl AK. Epidemiology of gallbladder cancer: a synthesis of recent data. J Natl Cancer Inst 1980;65:1209-14.

3. Lai CH, Lau WY. Gallbladder cancer--a comprehensive review. Surgeon 2008;6:101-10.

4. Kapoor VK, Benjamin IS. Resectional surgery for gallbladder cancer. Br J Surg 1998;85:145-6.

5. Chijiiwa K, Kai M, Nagano M, Hiyoshi M, Ohuchida J, Kondo K. Outcome of radical surgery for stage IV gallbladder carcinoma. J Hepatobiliary Pancreat Surg 2007;14:345-50.

6. Kai M, Chijiiwa K, Ohuchida J, Nagano M, Hiyoshi M, Kondo K. A curative resection improves the postoperative survival rate even in patients with advanced gallbladder carcinoma. J Gastrointest Surg 2007;11:1025-32.

7. de Aretxabala X, Roa I, Berrios M, et al. Chemoradiotherapy in gallbladder cancer. J Surg Oncol 2006;93:699-704.

8. Fong Y, Heffernan N, Blumgart LH. Gallbladder carcinoma discovered during laparoscopic cholecystectomy: aggressive reresection is beneficial. Cancer 1998;83:423-7.

9. Wakai T, Shirai Y, Hatakeyama K. Radical second resection provides survival benefit for patients with $\mathrm{T} 2$ gallbladder carcinoma first discovered after laparoscopic cholecystectomy. World J Surg 2002;26:867-71.

10. Shirai Y, Yoshida K, Tsukada K, Muto T. Inapparent carcinoma of the gallbladder. An appraisal of a radical second operation after simple cholecystectomy. Ann Surg 1992;215:326-31.

11. Foster JM, Hoshi H, Gibbs JF, et al. Gallbladder cancer: Defining the indications for primary radical resection and radical re-resection. Ann Surg Oncol 2007;14:833-40.

12. Kapoor VK, Pradeep R, Haribhakti SP, Sikora SS, Kaushik SP. Early carcinoma of the gallbladder: an elusive disease. $J$ Surg Oncol 1996;62:284-7.

13. Rao RV, Kumar A, Sikora SS, Saxena R, Kapoor VK. Xanthogranulomatous cholecystitis: differentiation from associated gall bladder carcinoma. Trop Gastroenterol 2005;26:31-3.

14. Bergdahl L. Gallbladder carcinoma first diagnosed at microscopic examination of gallbladders removed for presumed benign disease. Ann Surg 1980;191:19-22.

15. Shirai Y, Yoshida K, Tsukada K, Muto T, Watanabe H. Early carcinoma of the gallbladder. Eur J Surg 1992;158:545-8.

16. Shih SP, Schulick RD, Cameron JL, et al. Gallbladder cancer: the role of laparoscopy and radical resection. Ann Surg 2007;245:893-901.

17. National Cancer Registry Programme. Two-year Report of the Population Based Cancer Registries; 1997-1998. ICMR, Bangalore 2002.

18. Vitetta L, Sali A, Little P, Mrazek L. Gallstones and gall bladder carcinoma. Aust N Z J Surg 2000;70:667-73.

19. Roa I, de Aretxabala X, Araya JC, Roa J. Preneoplastic lesions in gallbladder cancer. J Surg Oncol 2006;93:615-23. 
20. Roa I, de Aretxabala X, Roa J, et al. Is gallbladder cancer a disease with bad prognosis? Rev Med Chil 2002;130:1295-302.

21. Prasad TL, Kumar A, Sikora SS, Saxena R, Kapoor VK. Mirizzi syndrome and gallbladder cancer. J Hepatobiliary Pancreat Surg 2006;13:323-6.

22. Darmas B, Mahmud S, Abbas A, Baker AL. Is there any justification for the routine histological examination of straightforward cholecystectomy specimens? Ann $R$ Coll Surg Engl 2007;89:238-41.

23. Taylor HW, Huang JK. 'Routine' pathological examination of the gallbladder is a futile exercise. $\mathrm{Br} J$ Surg 1998;85:208.

24. Dix FP, Bruce IA, Krypcyzk A, Ravi S. A selective approach to histopathology of the gallbladder is justifiable. Surgeon 2003;1:233-5.

25. Oommen CM, Prakash A, Cooper JC. Routine histology of cholecystectomy specimens is unnecessary. Ann R Coll Surg Engl 2007;89:738.

26. Bazoua G, Hamza N, Lazim T. Do we need histology for a normal-looking gallbladder? J Hepatobiliary Pancreat Surg 2007; 14:564-8.

27. Matthyssens LE, Ziol M, Barrat C, Champault GG. Routine surgical pathology in general surgery. Br J Surg 2006;93:362-8.

28. Srikanth G, Kumar A, Khare R, et al. Should laparoscopic cholecystectomy be performed in patients with thick-walled gallbladder? J Hepatobiliary Pancreat Surg 2004;11:40-4.
29. Lohsiriwat V, Vongjirad A, Lohsiriwat D. Value of routine histopathologic examination of three common surgical specimens: appendix, gallbladder, and hemorrhoid. World $J$ Surg 2009;33:2189-93.

30. Roa I, Araya JC, Villaseca M, Roa J, de Aretxabala X, Ibacache G. Gallbladder cancer in a high risk area: morphological features and spread patterns. Hepatogastroenterology 1999;46:1540-6.

31. Toyonaga $\mathrm{T}$, Chijiiwa $\mathrm{K}$, Nakano $\mathrm{K}$, et al. Completion radical surgery after cholecystectomy for accidentally undiagnosed gallbladder carcinoma. World J Surg 2003;27: 266-71.

32. Choi SB, Han HJ, Kim CY, et al. Incidental gallbladder cancer diagnosed following laparoscopic cholecystectomy. World J Surg 2009 Oct 13.[Epub ahead of print].

33. Kwon AH, Imamura A, Kitade H, Kamiyama Y. Unsuspected gallbladder cancer diagnosed during or after laparoscopic cholecystectomy. J Surg Oncol 2008;97:241-5.

34. Yamamoto H, Hayakawa N, Kitagawa Y, et al. Unsuspected gallbladder carcinoma after laparoscopic cholecystectomy. $J$ Hepatobiliary Pancreat Surg 2005;12:391-8.

35. Sharma A, Behari A, Sikora SS, Kumar A, Saxena R, Kapoor VK. Post-cholecystectomy biliary strictures: not always benign. J Gastroenterol Hepatol 2008;23:63-6.

36. Fong Y, Jarnagin W, Blumgart LH. Gallbladder cancer: comparison of patients presenting initially for definitive operation with those presenting after prior noncurative intervention. Ann Surg 2000;232:557-69. 